\title{
Cena
}

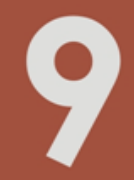

Dossiê Dança em Desdobramentos

PERIÓDICO DO PROGRAMA DE PÓS-GRADUAÇÃO EM ARTES CÊNICAS

INSTITUTO DE ARTES | DEPARTAMENTO DE ARTE DRAMÁTICA

UNIVERSIDADE FEDERAL DO RIO GRANDE DO SUL

\section{MOBILIDADE DAS PRÁTICAS CORPORAIS E ARTÍSTICAS NA DANÇA CONTEMPORÂNEA : TRÊS ESTUDOS DE CASO FRENTE ÀS PRÁTICAS DOMINANTES}

Suzi Weber

Doutora. Professora do Departamento de Artes Dramáticas-UFRGS 
estudos de caso, acompanhei, observei e analisei a prática artística de três bailarinos-criadores: Andrew de Lotbinière Harwood, Lin Snelling e Pamela Newel Eu os observei em seus processos de criação e em seus espetáculos durante o outono-inverno 2006-2007 em Montreal, em espaços de difusão alternativos. Com o propósito de identificar certas práticas que se apresentam como um vetor alternativo frente às práticas dominantes em dança contemporânea, apresento uma análise dos processos de criação e de difusão dos espetáculos The Sunday Project, de Pamela Newel, Perfoming Book, de Lin Senlling e Chalk, R.A.F.T. e Hark, ambos de Lobtinère Harwood.

\section{A PRÁTICA ENQUANTO EXPERIÊNCIA SOCIAL INSCRITA NO CORPO: HABITUS E CAPITAL CORPORAL}

Neste estudo, alguns aspectos das sociologias do corpo foram utilizados com o objetivo de colocar em relação o corpo, a sociedade e a dança. Neste sentido, a utilização de conceitos da sociologia do corpo, sobretudo de Pierre Bourdieu, visa reforçar a noção de prática enquanto experiência social e enquanto relação de poder inscrita no corpo. Os conceitos de Bourdieu ${ }^{2}$ (1994) de habitus, de capital e de campo são desenvolvidos e transpostos para minha pesquisa a fim de alimentar uma reflexão crítica em dança. É necessário sublinhar a difícil tarefa de compreensão de sua aparelhagem conceitual, assim como a preocupação, no decorrer deste estudo, de não reduzir seu pensamento. Neste estudo, trata-se de forma modesta, de procurar em seu pensamento um apoio e uma via reflexiva de acesso com o objetivo de compreender alguns aspectos da lógica das práticas artísticas observadas através dos dados empíricos.

O conceito de habitus foi o motor para compreender os aspectos, as características e o dinamismo das práticas do bailarino contemporâneo. Este conceito é fundamental para compreender como os bailarinos da dança contemporânea se predispõem a fazer suas escolhas. No entanto, o uso deste conceito, seguidamente sujeito a leituras controvertidas da sociologia, supõe uma compreensão e uma interpretação. Nesta pesquisa, o habitus é entendido como princípio mediador dos indivíduos e de suas condições da existência. Ele é também de uma importância primordial quando se trata de compreender a prática artística do bailarino, não somente como noção ligada à obra artística, mas enquanto ação do indivíduo que é resultado de uma aprendizagem e de 
uma incorporação. Este conceito permite pensar os bailarinos em uma troca constante com a realidade social da qual eles fazem parte, todos, indivíduos e sociedade, estando em processo de transformação. Outro aspecto importante deste conceito é que ele dá continuidade à tradição francesa de reflexão e teorização sobre o corpo. Ao reconhecer o corpo como uma condição permanente de experiência, Bordieu faz eco ao pensamento de Merleau-Ponty. A fenomenologia de Merleau-Ponty mostra o corpo como pivô da incorporação do sentido do mundo ("as formas do ser") e isto, considerando uma história cultural e pessoal. A sociologia de Bourdieu foi sensível às ideias de MerleauPonty e retoma a teoria do corpo para explicar como os indivíduos vão incorporar certos esquemas geradores de "formas de ser" de um grupo social ou de uma classe.

Se o habitus deve ser compreendido como disposição e tendência de agir, regido por uma racionalidade prática, é necessário conceber este conjuntamente com as noções de capital e campo a fim de poder explicar a gênese das práticas. Na teoria de Bourdieu (1994), capital é compreendido não somente como o acúmulo de bens e riquezas econômicos, mas como algo específico que adquire um valor num determinado tempo e espaço. Na dança, o corpo é uma dimensão fundamental que concentra um dos principais capitais da dança: o capital corporal. O capital corporal ${ }^{3}$ do bailarino compreende elementos como dimensões, forma e aparência. Mas compreende, sobretudo, as técnicas corporais de interação e de interpretação cinestésicas em dança, das quais o corpo é portador. A noção de campo, a partir de Bourdieu, referese a um microcosmo da vida social que se torna progressivamente autônomo através da história. Trata-se de considerar as instituições como configurações de relações entre agentes individuais e coletivos, ou seja, um espaço social estruturado a partir das posições que indivíduos e instituições ocupam. Cada campo tem seus próprios valores e regras, seus próprios interesses. A relação de força entre os indivíduos não consiste em um embate ou ação direta, mas sim numa luta pela ocupação de posições privilegiadas e de destaque. Transpondo a noção de campo de Bourdieu (1992), este estudo considera dois sub-campos: o subcampo de grande produção e o subcampo de produção

\footnotetext{
${ }^{3}$ A aquisição desse capital inclui formação e experiência. Poderíamos pensar numa audição, seja de dança clássica, contemporânea ou popular. Nela, o capital corporal se mostra através do domínio de técnicas de dança específicas bem como aspectos como a aparência e a postura. Isso vale tanto para detalhes como corte de cabelo e vestimentas, quanto para outros aspectos como a musculatura e a amplitude articular.
} 
restrita ${ }^{4}$. As práticas dominantes (BOURDIEU, 1982; ARBOUR, 1999) tendem a se concentrar no subcampo de grande produção, onde o poder econômico e simbólico se concentram. Segundo Michel e Ginot (2002), no caso da dança, as cenas dominantes pertencem a uma lógica econômica onde predomina a ideologia do espetáculo como objeto, onde o coreógrafo está ligado à origem da obra (o patrão, na economia política do espetáculo) e o espectador como consumidor de uma ordem estética.

A passagem do percurso entre a formação, a experiência e a prática dos bailarinos-criadores demonstra a relação estreita entre a aquisição de capital e a formação do habitus. As ligações realizadas por este estudo entre a prática de cada bailarino (formação e experiência) e as criações analisadas serviram para demonstrar a validade da transposição da noção polimórfica de capital forjada por Bourdieu para o campo da dança. Além disso, a compreensão dos modos de aquisição de capital dos bailarinos-criadores em cada estudo de caso permitiu entender como a formação desses bailarinos-criadores está ligada às suas criações. A compreensão do capital cultural, corporal, social e simbólico dos bailarinos demonstra as diferentes escolhas operadas a partir de um savoir-faire adquirido pela prática. Estas aquisições são "as boas cartas" que os bailarinos podem jogar enquanto valor certo no campo da dança contemporânea. Em cada estudo de caso, a compreensão da maneira pela qual cada bailarino construiu seu capital mostrou como cada um deles se move dinamicamente no campo, apontando também para alguns aspectos da evolução do próprio campo da dança contemporânea. A aquisição do capital específico em dança, incluindo formação e experiência artística, é o que permite aos bailarinos desfrutarem de reconhecimento por parte de seus pares, das instituições de difusão e de subvenção e do público. É este capital específico em dança que os legitima, principalmente no interior da dança contemporânea.

A noção de capital serve para compreender o capital específico da dança contemporânea enquanto recurso eficiente no campo, ou seja, enquanto armas de lutas e estratégias do campo. As práticas artísticas e corporais estão no centro destas armas e estratégias. De onde a importância de analisá-las.

O capital específico em dança foi compreendido enquanto propriedade global ao campo da dança contemporânea. No entanto, esta apropriação está dividida em grupos e subgrupos. É importante destacar que nos três estudos

\footnotetext{
${ }^{4}$ É na obra As regras da arte (1992) que Bourdieu empreende uma análise da categoria histórica da percepção artística. Nesta obra, ele refere-se ao "subcampo de produção cultural restrita", isto é a produção que não visa o mercado cultural em larga escala.
} 
de caso, a aquisição de práticas em dança se faz nos diálogos entre a dança e as fronteiras tênues da arte contemporânea. Em outros termos, as práticas em dança dos três estudos de caso mantem proximidade com outras práticas artísticas, somáticas e de outros meios e linguagens. No entanto, a dança contemporânea permanece como pano de fundo das práticas dos bailarinos participantes desta pesquisa. A dança é o campo no qual os três participantes situam suas criações e procuram colocar em evidência seus valores, suas ideias e suas concepções em dança. Uma das estratégias do campo é a evolução em torno da noção de coreografia. Os bailarinos-participantes contribuem, por meio de suas criações, na evolução desta noção que é cada vez mais ampliada.

\section{POLARIZAÇÃO DAS PRÁTICAS: ENTRE O SUBCAMPO DE GRANDE PRODUÇÃO E SUBCAMPO DE PRODUÇÃO RESTRITA}

No presente estudo, as práticas do bailarino contemporâneo foram analisadas procurando polarizá-las entre dois subcampos. As criações analisadas nos três estudos de caso se inscrevem no subcampo de produção restrita pelo fato de serem produções pontuais, modestas e de se apresentarem em espaços de difusão alternativos, lugares reconhecidos como espaços de renovação da paisagem artística de Montreal. Estes lugares, à margem do grande público, são os espaços onde os bailarinos-criadores estudados apresentam suas criações. Estes espaços ${ }^{5}$, uns mais institucionalizados e outros ainda instáveis, são uma parte fundamental do subcampo da produção restrita em Montreal. Estes lugares contribuem para legitimar certos artistas, ao fornecer-lhes suportes logísticos para suas criações, pois compartilham afinidades artísticas com eles. As práticas analisadas nos três estudos de caso encontram um terreno fértil no subcampo da produção restrita, num contexto que favorece sua existência, o que é uma das razões pelas quais a sobrevivência desses espaços é da mais alta importância. Estes espaços são igualmente importantes porque são utilizados tanto por jovens artistas emergentes como pelos artistas mais experientes, como é o caso dos bailarinos deste estudo. Outro aspecto que situa as criações analisadas no subcampo de produção restrita é que estas estão menos preocupadas com as expectativas do grande público. No subcampo da grande produção, de maneira geral, será difícil produzir criações com base na

\footnotetext{
${ }^{5}$ As questões relativas aos espaços de difusão no subcampo de produção restrita e no subcampo de grande produção, do qual eu conheço a relevância e a complexidade, mereceriam uma pesquisa e uma análise mais pontuais que escapam as questões principais desta pesquisa.
} 
improvisação, visto que as concepções diretivas de suas produções promovem corpos gloriosos onde a excelência do corpo tende à superação física.

A polarização das práticas entre estes dois subcampos serve para destacar as práticas mais representativas entre estes subcampos. No entanto, alguns trânsitos e passagens dos artistas e das práticas entre os subcampos não tinham sido antecipados no início do estudo. Entretanto, os três estudos de caso mostram diferentes formas de artistas e práticas que transitam entre os subcampos. Esta pesquisa chega, portanto, a apreender contrastes e oposições em um campo bastante impreciso - tarefa difícil dada a multiplicidade criativa das ofertas estéticas e de temporalidades internas próprias à arte contemporânea. De forma geral, a arte contemporânea é suficientemente dinâmica e menos institucionalizada quando comparamos a outras esferas da sociedade. A compreensão da oposição de certas práticas é útil a fim de compreender seus aspectos distintos, assim como dos conhecimentos específicos do campo da dança contemporânea e este, mesmo se este estudo reconhece a porosidade entre os ditos subcampos. O recorte proposto por este estudo também serviu de estratégia para circunscrever as criações analisadas, nas quais certas práticas se diferenciam das práticas dominantes.

Tendo como base um quadro teórico formado a partir de diversos autores $^{6}$, concluo que o subcampo de grande produção tende a uma normalização do corpo do bailarino por meio das práticas dominantes que privilegiam um corpo glorioso, disciplinado, silencioso e sofredor. Essas práticas do subcampo de grande produção deixam entrever aspectos de um certo academicismo ligado à institucionalização da dança e às imposições de produção a partir do fim dos anos 1980 e principalmente 1990. O ponto de vista crítico de diferentes autores especializados na dança contemporânea aponta uma categoria de práticas em dança contemporânea que se estabeleceram em uma zona de inércia, práticas que resistem à evolução, perpetuando-se a fim de garantir sua posição dominante. As práticas no centro do subcampo de grande produção reforçam certas hierarquias como a distância entre coreógrafo-diretor artístico e jovens bailarinos ou aquele entre os processos de

\footnotetext{
${ }^{6}$ Tendo como base uma reflexão crítica em dança contemporânea a partir de textos de certos autores (Faure, 2001; Fortin, 2008; Guigou, 2004; Launay, 2001; Louppe 1997; Sorignet, 2006; Thomas 2003), parto do pressuposto de que existe uma certa padronização de corpos dançantes em dança contemporânea, embora haja uma diversidade e multiplicidade de propostas artísticas. Segundo os autores citados acima, valores como verticalidade, força e precisão ainda perduram fortemente na dança contemporânea.
} 
criação e representação. Elas supõem também modelos de criação rigorosos nos quais existe uma valorização excessiva da juventude. Muitos autores ${ }^{7}$ sublinham as grandes companhias como plataforma destas práticas já que elas concentram e monopolizam os maiores orçamentos e contribuem para perpetuar a uniformidade da criação coreográfica e a padronização do corpo dançante.

\section{OS TRÊS ESTUDOS DE CASO}

Os três estudos de caso desta pesquisa dão exemplos da maneira pela qual alguns artistas da dança contemporânea propõem, de maneira reduzida, difusa e pontual, outros valores estéticos e outras estruturas de organização que podem se revelar como uma opção de mudança face às práticas dominantes. Os três estudos de caso respondem, de diferentes maneiras, à principal questão da pesquisa deste estudo, a saber: como certos bailarinoscriadores se distinguem em relação às práticas dominantes em dança contemporânea? Cada estudo de caso apresenta nuances e aspectos diferentes que servem para explicitar a complexidade dos diversos aspectos das práticas artísticas, assim como a dificuldade de lhes generalizar. Os parágrafos seguintes descrevem certas particularidades resultantes da análise de cada estudo de caso.

No estudo de caso de Pamela, este estudo conclui que sua prática se caracteriza tanto por uma formação tradicional quanto por uma formação sólida, ligada aos nichos da improvisação em dança relacionados à educação somática $^{8}$. No subcampo de produção limitada, onde Pamela assina como coreógrafa e colaboradora de suas criações, a improvisação sobre a cena tem um papel fundamental, visto que é através dessa prática que Pamela pode se afirmar como artista. Por meio da improvisação, Pamela coloca em cena um corpo receptivo, aberto aos movimentos cotidianos, às questões inesperadas, às possíveis trocas com outros artistas, em direção aos elementos tais como as mídias e a escrita, e finalmente em direção ao outro. Esta abertura promove uma relação com o corpo menos disciplinada, já que as noções do espaço e do tempo são mais difusas e que a superação física é menos rigorosa. A prática artística de Pamela se distingue pela integração de um questionamento

\footnotetext{
${ }^{7}$ Entre outros já citados, encontramos Louppe, 1997; Fortin, 2008, Martin, 2006.

${ }^{8}$ A Educação Somática é uma disciplina em emergência, que se constitui a partir da reunião de diferentes práticas de educação pelo movimento, tais como os métodos desenvolvidos por $F$. Matias Alexander, Moshe Feldenkrais, Irmgard Bartenieff, entre outros. No Brasil, cabe destacar a atuação de Klaus Vianna e de Ivaldo Bertazzo, que desenvolveram métodos pessoais de estudo e educação do movimento humano que podem ser caracterizados como métodos de Educação Somática. Ver Fortin (1998) e Weber (2004).
} 
constante. Ela mistura os elementos da criação com um pensamento reflexivo. Sua formação em educação somática e sua formação universitária são as fontes desta dimensão reflexiva de sua prática. Além disso, a improvisação sobre a cena e certos aspectos da performance favorecem o refinamento de sua presença por meio da desconstrução de mecanismos da representação. Finalmente, seu capital corporal opera de modo diferente nos dois subcampos. Por exemplo, no seio das grandes companhias, sua prática de improvisação está a serviço das concepções diretivas dos coreógrafos; em suas criações autorais ou em colaboração, a improvisação em cena oferece uma possibilidade de troca com outros artistas e outros meios e linguagens.

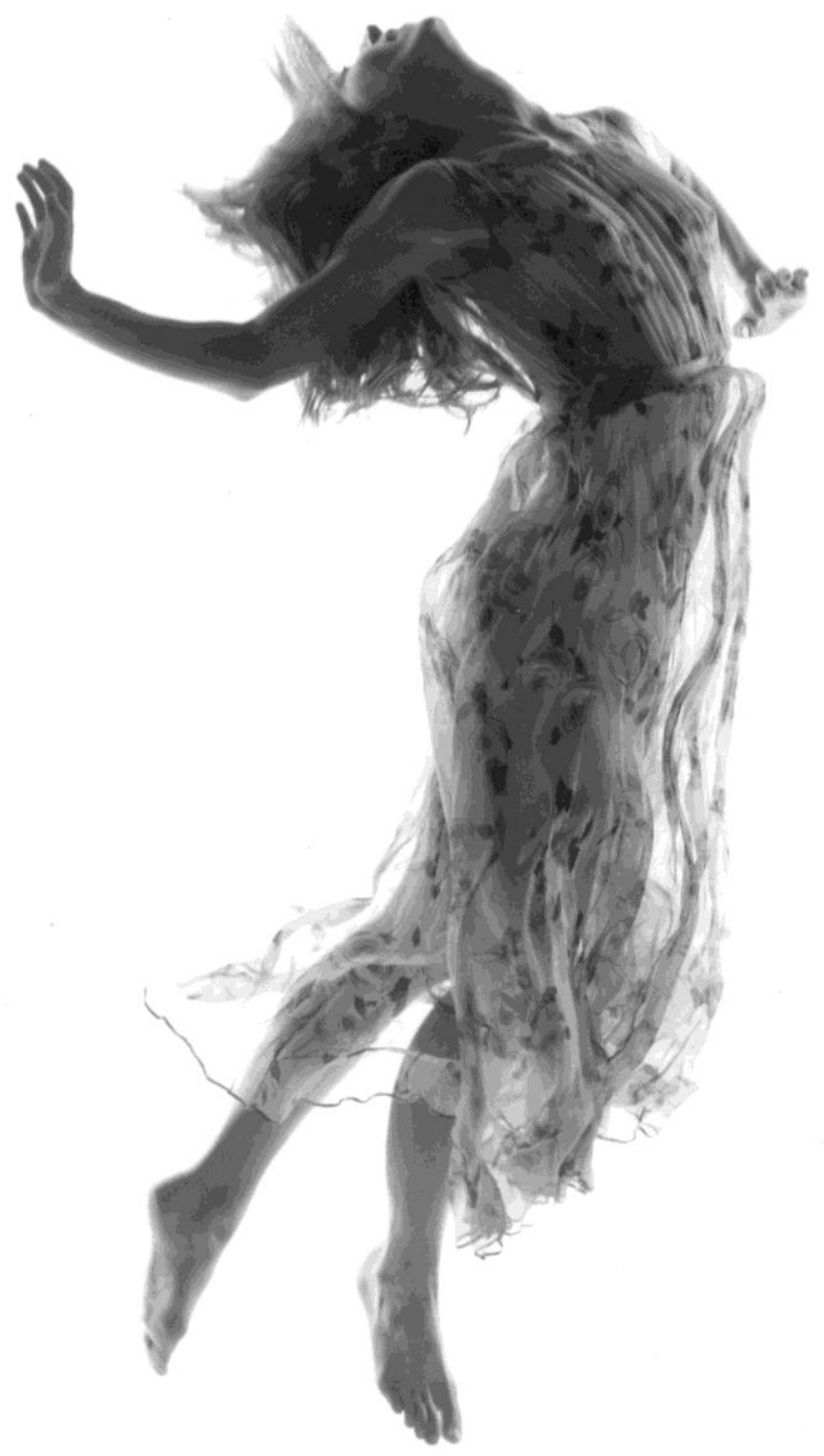




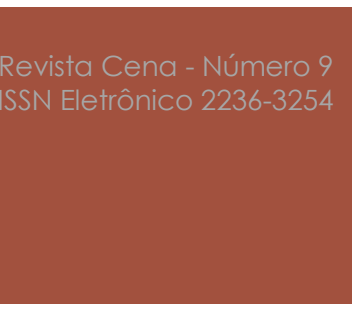

Figura 1 : Pamela Newell. Foto de divulgação do espetáculo Pluriel apresentado no teatro Tangente em Montréal.

No estudo de caso de Lin, esta pesquisa conclui que a força de sua prática reside principalmente na sua formação e sua experiência artística interdisciplinar nas fronteiras tênues das artes. A integração dos elementos tais como a escrita, as mídias e certos elementos das artes visuais (desde sua primeira juventude) faz parte de sua prática em dança contemporânea e confirma sua aproximação interdisciplinar. Os temas recorrentes do corpo, do espaço e das paisagens aparecem em seus textos e nas suas criações e servem também de dispositivos artísticos. Estes elementos contribuem com criações que escapam à composição exclusiva do movimento ou de técnicas corporais. Desta maneira, Lin se afirma enquanto artista com uma noção coreográfica segundo a qual a improvisação, a performance e a interdisciplinaridade contribuem para renovar a criação coreográfica. Estes elementos favorecem as práticas nas quais a hierarquia entre processos e 0 resultado é menos clara, onde estes dois elementos se aproximam. Além disso, a ligação entre artista e público é modificada. A dimensão exploratória de sua prática favorece uma proximidade com o espectador, convidando-o a participar de sua criação de maneira mais direta e íntima. Eu qualifico sua relação com o corpo como participativa. Neste caso, é a expansão da cinesfera do bailarinocriador em direção à cinesfera do espectador, são conhecimentos somáticos do bailarino-criador que são direcionados ao público de maneira mais ativa. Diálogo entre artista e público que valoriza a troca cinestésica e social do corpo. 

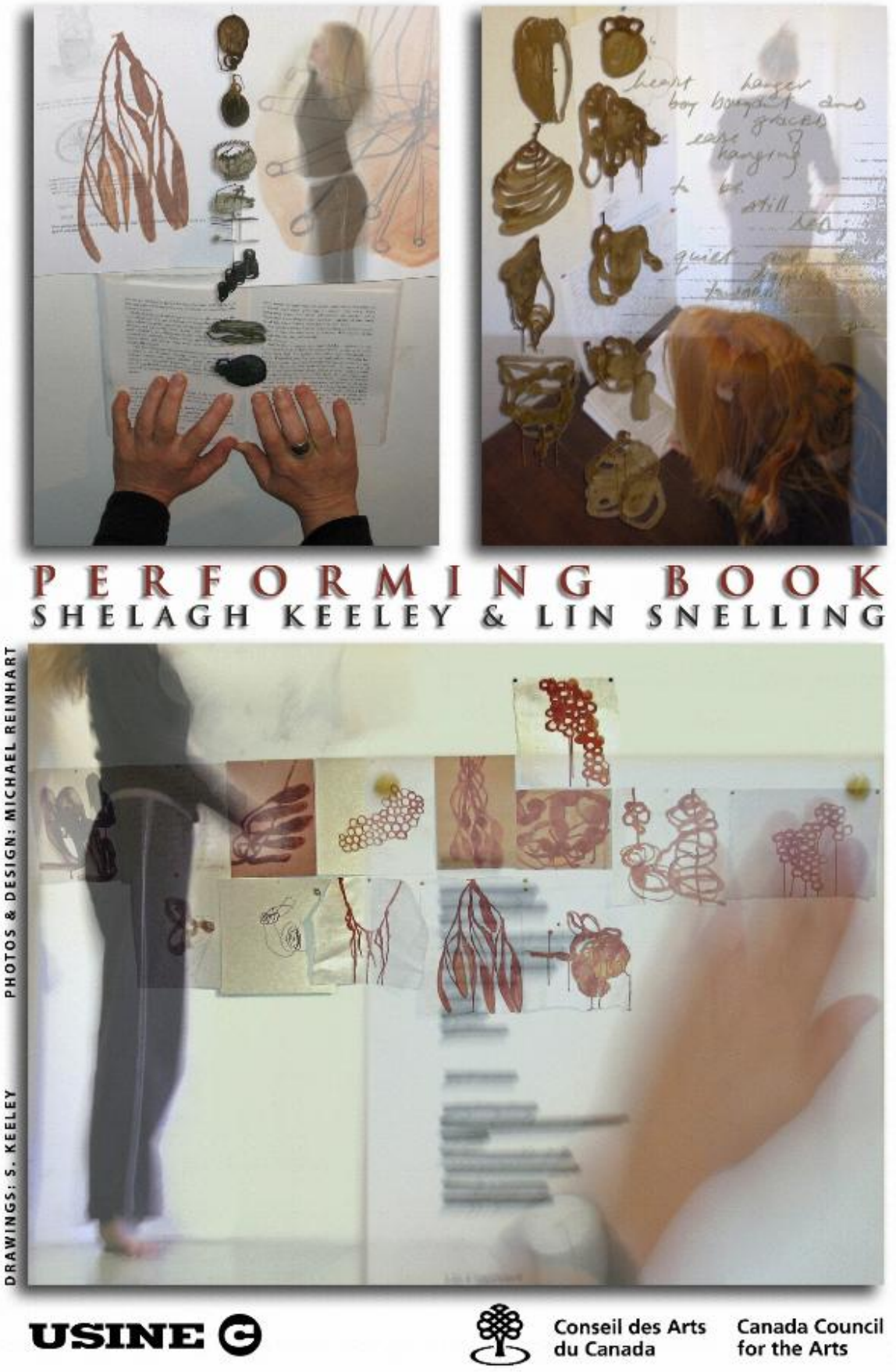

Figura 2: Convite da criação de Lin Snelling, Performing Book.

No estudo de caso de Andrew, foi possível observar que a improvisação em cena nos diferentes contextos aparece como uma ferramenta de renovação 
da criação coreográfica. Improvisar é considerado uma arte à parte e também como uma prática que ultrapassa as fronteiras da arte. No conjunto de sua experiência em improvisação, sua associação à comunidade do Contact Improvisation constitui uma parte fundamental e significativa de seu capital corporal, cultural e social. Sua prática dá prioridade ao movimento relaxado e a aspectos tridimensionais do corpo. Sua prática se inscreve nos grupos de artistas onde a colaboração no contexto das pequenas produções de autogestão se tornam uma constante. $O$ estudo de caso de Andrew é bem explícito, no sentido em que o Contact Improvisation lhe oferece um vetor de mudança no que diz respeito às estruturas hierarquizadas das companhias. $A$ versatilidade dos papéis nos quais Andrew se vincula, enquanto bailarino, coreógrafo, produtor, convidado e professor no meio da dança contemporânea se contrapõe à rigidez dos papéis tradicionais do mercado da dança contemporânea. Além disso, neste contexto do Contact Improvisation, Andrew desenvolveu um forte capital social entre bailarinos e não-bailarinos, o que demonstra uma abertura e uma forte dimensão inclusiva na maneira de perceber a prática da dança. Este capital social Ihe permite estabelecer diferentes redes na dança através dos coletivos temporários, das criações pontuais e das colaborações as mais diversas. Estas redes mostram as atitudes de cooperação multiculturais e de sociabilidades renovadas, caracterizadas pelas organizações espalhadas por todo o mundo. A exemplo do Contact Improvisation, Andrew promove trocas aceitando convites de espetáculo e oficinas mas também oferecendo ${ }^{9}$. Deste modo, Andrew participa do campo da dança contemporânea, trazendo uma relação para o corpo interativo, colocado em rede.

\footnotetext{
${ }^{9}$ Andrew promove, através de espetáculos e oficinas, bailarinos vindos dos mais diversos países e cidades que não residem em Montréal.
} 


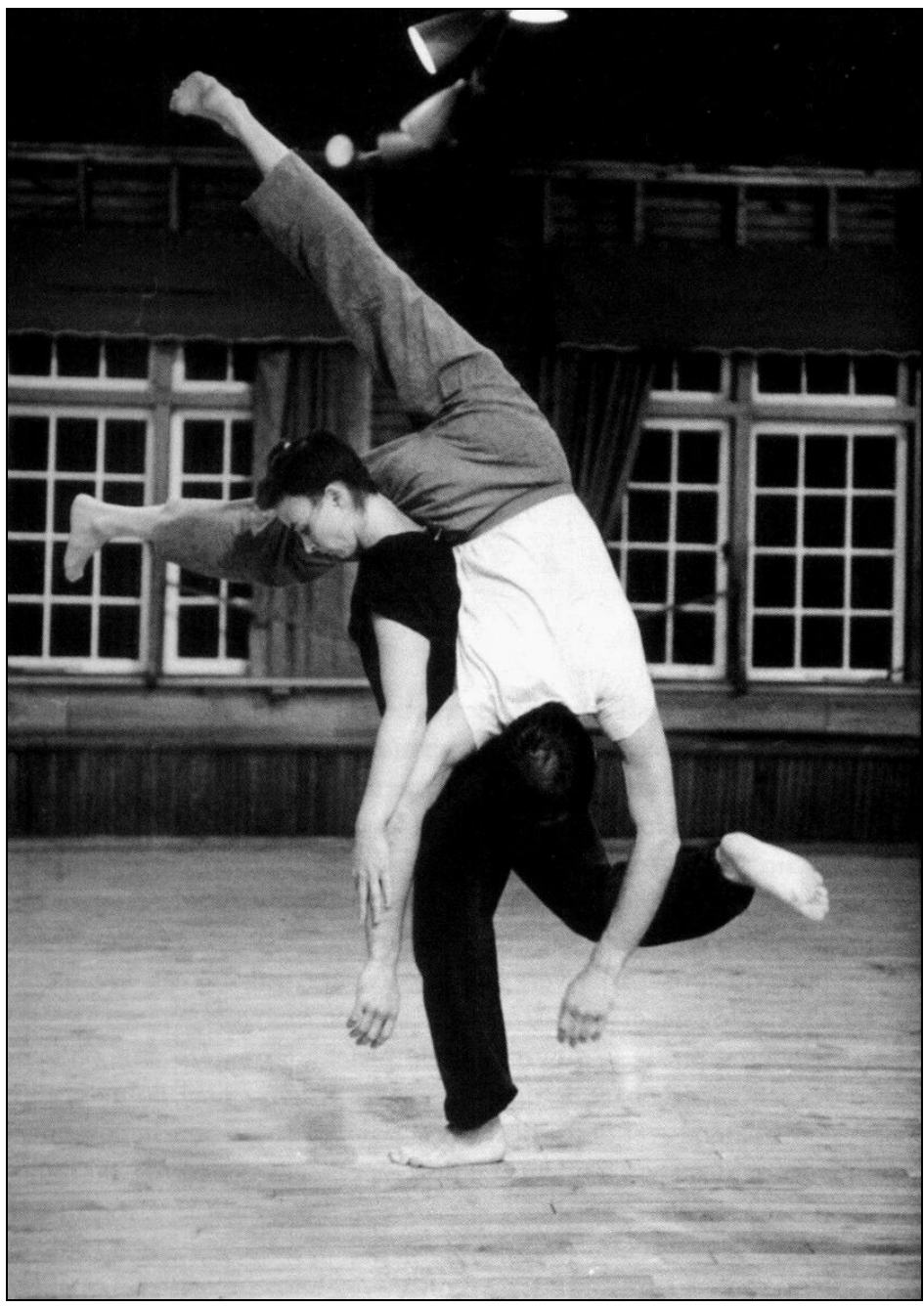

Figure 3 : Andrew Harwook e Karen Nelson em duo de Contact Improvisation. Fonte: Cohen (1993, p. 289). Foto de Bill Arnold.

Por meio de caminhos singulares, todos os meus três pesquisados construíram um capital específico em dança diferenciado e um conjunto particular de práticas numa relação dinâmica entre sua singularidade e os aspectos próprios da dança contemporânea. De fato, os três participantes desta pesquisa apresentam, de diferentes maneiras, práticas recorrentes que se revelam uma solução de alternativa no que diz respeito às práticas dominantes. Estas práticas não podem necessariamente ser consideradas como novas: elas são principalmente o fruto da evolução do campo da dança contemporânea. São antigas questões que encontram um terreno fértil no subcampo da produção restrita. Hoje, os artistas não acreditam mais, como os 
antigos vanguardistas, nas transformações radicais e inovadoras; entretanto, é verdade que se distanciando do sistema dominante, eles desenvolvem certas práticas que podem renovar parcialmente a dança contemporânea. Estas práticas desfrutam de um relativo frescor estético, menos hierarquizadas do que as práticas dominantes, já que menos institucionalizadas. Nas criações analisadas, estas práticas contrastam com as práticas dominantes, propondo uma relação com o corpo de modo menos disciplinado.

As criações observadas neste estudo, nutridas pela improvisação em dança, estão em sintonia com a arte contemporânea no seu registro amplamente experimental. Estas criações se apresentam parcialmente liberadas de obrigação de conclusão da obra, da divisão disciplinar de linguagem e de sucesso diante do grande público. Como destaca Jimenez (1999), as criações que se encontram no registro de experimentação dão uma continuidade ao que as vanguardas do início do século nos ensinaram, a saber, que a experimentação não está em contradição com a obra. O desafio teórico deste estudo foi então compreender a prática que anima estas criações, compreendendo a sua coerência, seus valores escondidos e seus percursos cheios de imprevistos. Para dar conta disso, este estudo mobiliza referências teóricas confrontadas aos dados empíricos observadas nos estudos de caso.

A análise dos dados foi realizada buscando relações de oposição frente às práticas dominantes identificadas a partir do referencial teórico já explicitado. O quadro abaixo apresenta uma síntese das práticas analisadas, em contraste às práticas consideradas como dominantes. É importante mencionar que tais práticas funcionam enquanto práticas dominantes no momento em que elas se encontram associadas a outras práticas consideradas igualmente dominantes, formando assim um conjunto. Por exemplo, em uma criação de grande produção há uma tendência a uma lógica econômica de grande produção (oferta de acordo com a procura) e será difícil escapar às pressões de uma certa conjuntura do poder econômico. As práticas dominantes se encontram polarizadas sobre certas tendências, mas elas somente são 
eficazes a partir de um conjunto onde as hierarquias mais tradicionais se estabelecem a fim de manter seu domínio e posição.

Tabela 1: Síntese de aspectos das práticas analisadas

\begin{tabular}{|c|c|}
\hline $\begin{array}{l}\text { SUBCAMPO DE GRANDE } \\
\text { PRODUÇÃO } \\
\text { (QUADRO TEÓRICO) }\end{array}$ & $\begin{array}{l}\text { SUBCAMPO DE PRODUÇÃO RESTRITA } \\
\text { (CRIAÇÕES OBSERVADAS) }\end{array}$ \\
\hline Grandes produções & Produções modestas \\
\hline Teatro de grande amplitude & Salas e estúdios \\
\hline Bailarinos e intérpretes & $\begin{array}{l}\text { Colaborador, } \quad \text { coreógrafo-intérprete, } \\
\text { improvisador }\end{array}$ \\
\hline Coreografia finalizada & Criação aberta ou participativa \\
\hline $\begin{array}{lll}\begin{array}{l}\text { Estrutura } \\
\text { companhia }\end{array} & \text { de } & \text { grande } \\
\end{array}$ & Criações a partir de ligações temporárias \\
\hline Obras de repertório & Criações pontuais \\
\hline $\begin{array}{lll}\begin{array}{l}\text { Coreógrafo } \\
\text { exclusivo }\end{array} & \text { como } & \text { criador } \\
\end{array}$ & Dimensão criativa da obra dividida \\
\hline $\begin{array}{l}\text { Distância entre processos e } \\
\text { espetáculo }\end{array}$ & Aproximação entre processos e espetáculo \\
\hline $\begin{array}{|ll|}\text { Improvisação } & \text { durante } \\
\text { o processo de criação } & \\
\end{array}$ & Improvisação sobre cena \\
\hline $\begin{array}{l}\text { Processos baseados na } \\
\text { repetição }\end{array}$ & Processos baseados na exploração \\
\hline Síntese da criação definida & Estruturas parciais da criação \\
\hline $\begin{array}{l}\text { Utilização do espaço limitado à } \\
\text { cena a italiana }\end{array}$ & Utilização do espaço fora da cena italiana \\
\hline $\begin{array}{l}\text { Dicotomia de julgamento } \\
\text { (bem feito / mal feito) }\end{array}$ & Táticas de relativização do julgamento \\
\hline $\begin{array}{l}\text { Momentos espetaculares ou } \\
\text { exóticos }\end{array}$ & $\begin{array}{l}\text { Inclusão do vazio e do tédio como } \\
\text { sensações aceitas }\end{array}$ \\
\hline
\end{tabular}




\begin{tabular}{|l|l|}
\hline Espectador passivo & $\begin{array}{l}\text { Espectador como convidado, testemunha ou } \\
\text { participante }\end{array}$ \\
\hline Papéis fixos dos participantes & $\begin{array}{l}\text { Pluralidade dos papéis e das funções dos } \\
\text { participantes na criação }\end{array}$ \\
\hline $\begin{array}{l}\text { Mídias em justaposição com a } \\
\text { dança }\end{array}$ & Interação com as mídias e a dança \\
\hline $\begin{array}{l}\text { Valorização dos movimentos } \\
\text { virtuosos }\end{array}$ & $\begin{array}{l}\text { Redução da valorização dos movimentos } \\
\text { virtuosos }\end{array}$ \\
\hline Uso das técnicas clássicas & $\begin{array}{l}\text { Técnicas de improvisação e de educação } \\
\text { somática valorizadas }\end{array}$ \\
\hline $\begin{array}{l}\text { Corpo visando a superação } \\
\text { física }\end{array}$ & $\begin{array}{l}\text { Inclusão dos corpos cotidianos, ordinários e } \\
\text { inoperantes }\end{array}$ \\
\hline Corpo de aparência jovem & $\begin{array}{l}\text { Diversidade corporal ("bons e velhos } \\
\text { corpos”) }\end{array}$ \\
\hline Corpo vigoroso & Corpos relaxados \\
\hline $\begin{array}{l}\text { Relação do corpo estética e e } \\
\text { instrumental }\end{array}$ & $\begin{array}{l}\text { Corpos mais receptivos, interativos e } \\
\text { participativos }\end{array}$ \\
\hline
\end{tabular}

\section{ALGUMAS PRÁTICAS OBSERVADAS EM UMA RELAÇÃO DINÂMICA: IMPROVISAÇÃO, COLABORAÇÃO, EDUCAÇÃO SOMÁTICA E PERFORMANCE}

Nas criações observadas, a improvisação em cena oferece aos bailarinos a possibilidade de serem mais autônomos, graças a uma ampla gama de possibilidades de diálogos entre os artistas, entre os elementos de cena e com o público. A improvisação se apresenta também como uma prática de frescor, aberta ao inesperado, ao acaso. No entanto, sua apreensão e sua legibilidade são difíceis de compreender pelo público em geral, dada sua dimensão imediata. Esta dimensão, aparentemente espontânea, é resultado de um longo processo de aprendizagem e de incorporação nos nichos de improvisação no seio da dança contemporânea. Nos três estudos de caso, a 
improvisação aparece amalgamada a aspectos da educação somática, da performance e da interdisciplinaridade. Nesta pesquisa, a improvisação nas criações observadas $^{10}$ aparece como uma prática capaz de renovar a noção de coreografia. O Contact Improvisation, enquanto técnica de improvisação, aparece como uma forte influência, principalmente para Pamela e Andrew. Outro aspecto fundamental é que a improvisação aparece como uma prática que reforça a originalidade do bailarino, valorizando-o enquanto criador, o que confere uma forma de capital simbólico muito reconhecido no campo da dança.

A educação somática enquanto, disciplina portadora de numerosas técnicas, presentes nas diferentes formações de cada bailarino, afirma-se como uma prática que valoriza a consciência e que respeita os limites do corpo. Para os três bailarinos, a compreensão de que o corpo pode aprender e experimentar através do seu próprio relaxamento é visível e legível em suas criações, e ela demonstra o distanciamento de certos valores tradicionais, como a importância da superação física. De maneira mais específica, a influência da educação somática é visível nas cenas onde os bailarinos massageiam-se e manipulam-se uns aos outros, assim como nos movimentos realizados de forma relaxada no solo. Desse modo, os corpos distendidos, os deslizamentos no solo e os movimentos cotidianos presentes na cena constituem aspectos que mostram a relação dos procedimentos de criação com as técnicas somáticas. Nas entrevistas, nos textos e nos desenhos, as referências à anatomia do corpo e a diferentes técnicas somáticas foram seguidamente destacadas. A educação somática aparece também enquanto prática reflexiva, a partir do momento em que os bailarinos se questionam sobre eles mesmos, sobre suas sensações, sobre seus estados corporais. Sendo assim, a educação somática se apresenta como uma preocupação subjacente de bem estar do corpo.

\footnotetext{
${ }^{10}$ Nas criações observadas, a improvisação se apresenta de diferentes maneiras: seja a improvisação aberta como em Chalk e Hark, ou a partir da temática da memória como em R.A.F.T. 70, ou ainda a partir de elementos interdisciplinares como em The Sunday Project e Performing Book.
} 
A atração e a valorização dos movimentos cotidianos é, desse modo, uma prática recorrente nas criações observadas. Como destacado acima, nas criações analisadas, algumas ações como caminhar, sentar-se, olhar, massagear, manipular o corpo, falar, cantar e dialogar são muitas vezes evocadas. Para além da educação somática, outro aspecto importante, que favorece os movimentos e os gestos cotidianos, refere-se ao fato de que a composição do movimento não é mais a única maneira de conceber uma coreografia. Outros elementos podem ser utilizados enquanto fonte de criação, como situações, dispositivos, gestos e lugares que reduzem, pela sua presença, a importância dos movimentos refinados e das exigências físicas. Nas criações observadas, de maneira geral, existe uma minimização da importância da técnica corporal no conjunto da criação. Observemos outro aspecto próprio da improvisação: a inclusão de movimentos menos hierarquizados, que remetem ao tédio e ao vazio, e que podem ser aceitos como fazendo parte da criação - reduzindo desta maneira os aspectos espetaculares da criação. Esta inclusão, realizada pelos bailarinos participantes desse estudo, decepciona uma das expectativas importantes do público, a saber, os movimentos virtuosos ligados à superação física. Isto demonstra certa autonomia dos bailarinos-criadores diante das expectativas do grande público.

A prática da criação em colaboração, encontrada nas criações observadas, demonstra uma prática recorrente, que prejudica a divisão tradicional entre o coreógrafo e o intérprete, fortemente hierarquizada. Os participantes desta pesquisa apresentam-se, nos programas dos espetáculos, como colaboradores, improvisadores, artistas independentes, coreógrafosinterprétes ou performers. Eles são, dessa maneira, capazes de ativar relações menos tradicionais, mas, no entanto, mais operacionais em termos de arte, propondo uma alternativa ao modelo dominante do sub-campo da grande produção. A prática de colaboração favorece igualmente as criações pontuais e as trocas multiculturais, ao propor organizações mais instáveis e mais 
dinâmicas. Essa prática marca um vetor de socialização, em uma relação muitas vezes menos hierarquizada entre os participantes da criação. A assinatura da criação se torna, dessa maneira, compartilhada e mais igualitária. Os bailarinos são aqui reconhecidos como colaboradores, bailarinos-criadores, em um nível equivalente ao do coreógrafo ou ao de outros artistas de diferentes mídias que participam da criação. As criações observadas e analisadas são o fruto da prática em colaboração que, mais do que a noção de apresentação da obra, propõe uma apresentação em rede.

Os aspectos interdisciplinares das criações, seja por meio da utilização de mídias, seja através do trânsito entre a dança e outras artes ou linguagens, promove situações que escapam ao uso instrumental do corpo. Nas criações observadas, a interdisciplinaridade foi realizada através das relações da dança com a literatura, a escrita, a música $e$ as artes visuais. Essa interdisciplinaridade, que se situa nas zonas de fronteiras onde os limites da categorização são sacudidos, é também uma característica dos aspectos influentes da performance. Além disso, a performance coloca em evidência a falta de finalização da produção. Flexibilizando a noção de representação, a performance favorece o discurso reflexivo ou auto-reflexivo, nos quais os artistas se apresentam em seu próprio nome.

O fato de que os três artistas atribuem um papel mais ativo ao espectador, de diferentes maneiras e com graus de participação variados, é uma prática que os distingue face às práticas dominantes. Nas criações observadas, notamos alguns exemplos nos quais os bailarinos-criadores procuram o diálogo com o público,dirigindo-se a ele eventualmente de maneira direta durante os espetáculos ou convidando-o a testemunhar sobre o aqui e $o$ agora, característica própria das criações com base na improvisação. Este é um aspecto da imediaticidade da improvisação, onde a presença de um único espectador transforma a criação. Nos exemplos mais radicais, o espectador é convidado a aderir uma dinâmica de convidado, de testemunha e de colaborador, prática que solicita ou convida o espectador a participar de 
maneira mais direta da criação. Esta dimensão de imediaticidade e de participação é aquela que identificamos nos aspectos fundamentais da performance. Esta abertura face ao público permite deixar uma zona aberta na criação, de tal forma que a criação não seja jamais concluída, já que participativa. Trata-se de estabelecer uma possibilidade de troca de muitas dimensões, onde o estatuto do criador balança em direção ao outro. Mesmo parcial, a busca de trocas com o público é realizada por meio da intensificação da imediaticidade da criação, do diálogo direto com o espectador ou através de situações inusitadas. Tudo isso revela processos que constituem outros meios criativos além dos modelos autoritários e/ou diretivos da criação para o outro. É nisto que reside a dimensão política da dança contemporânea, na qual a possibilidade de participação e, por consequência, da percepção é libertada. $O$ aspecto de frontalidade das obras coreográficas, uma das lógicas visuais dos modelos dominantes, só será alterado de maneira mais radical a partir do momento em que ele solicita e ativa, de maneira dinâmica, o corpo do espectador.

A apropriação dos conceitos de outros domínios, como os da sociologia do corpo, foi importante para este estudo para compreender as práticas da dança a partir de seus aspectos cruciais, de forma a confrontar um conhecimento específico e uma racionalidade prática própria no campo da dança. Ela foi igualmente importante no sentido em que permitiu a compreensão de que uma prática artística em constante evolução evolui em um certo contexto, em um certo mundo. Por meio deste estudo, é possível compreender os bailarinos criadores em uma troca dinâmica com a realidade que os constroi e que eles mesmos ajudam a construir. Distanciando-se das práticas dominantes, eles demarcam sua autonomia parcial e se afirmam enquanto produtores artísticos mais do que produtos.

É fundamental para este estudo estabelecer certas oposições, que se encontram polarizadas entre os subcampos da dança contemporânea, pois essas oposições cristalizam as lutas no campo. As práticas analisadas no 
presente trabalho identificam as práticas distintas que encontram um terreno fértil no subcampo de produção restrita. Essas características sugerem a evolução, o dinamismo e as modificações no que concerne ao habitus do bailarino no seio da dança contemporânea. No sub-campo da grande produção, o caráter de legibilidade da técnica associada à excelência e à disciplina dos bailarinos no conjunto das obras é fundamental. Estes aspectos respondem às coreografias tendo como predominância e primazia a composição do movimento. Em contrapartida, no subcampo de produção limitada, as técnicas são mais interdisciplinares e, em consequência, menos legíveis, permitindo assim uma relação com o corpo menos disciplinado. Nas criações observadas, os bailarinos buscam um olhar sobre eles mesmos e sobre o outro por meio da improvisação sobre cena, nutridos pela aproximação das técnicas somáticas dos bailarinos e pela desconstrução da representação promovida por certos aspectos da performance. São os aspectos da prática dos participantes deste estudo que são construídos como esquema corporal por meio de uma longa imersão por parte dos bailarinos-criadores nos nichos artísticos fora das "grandes cenas". Além de mostrar, o leitmotiv dessas práticas é dialogar. Na maioria das criações observadas, a via do conhecimento proprioceptiva envolve expressamente o espectador. Os verbos que caracterizam as práticas analisadas neste estudo circunscritas ao subcampo de produção limitada são antes de tudo interagir, trocar e dialogar. As práticas analisadas nesses três estudos de caso propõem trocas, percepções e gestões de criações renovadas e, finalmente, novas sociabilidades em dança contemporânea que determinam uma relação do corpo de modo mais receptivo, interativo e participativo.

\section{REFERÊNCIAS BIBLIOGRÁFICAS}




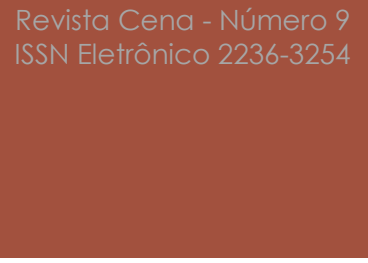

ABOUR, R. M. L'art qui nous est contemporain. Montreal: Éditions Prendre Parole, 1999.

BOURDIEU, P. Raisons pratiques. In: Les règles de l'art: genèse et structure du champ littéraire. Paris: Seuil, 1992.

FAURE, S. Corps, savoir et pouvoir. Sociologie historique du champ chorégraphique, Lyon: Presses Universitaires de Lyon, 2001

FORTIN, S. When Dance Science and Somatics Enter the Dance Technique Class. Kinesiology and Medicine for Dance, 15(2), Spring/Summer, 1993.

FORTIN, S. (org.). Danse et santé : du corps intime au corps social. Montreal: Presses de l'Université du Québec, 2008.

GUIGOU, M. La nouvelle danse française. Paris: L'Harmattan, 2004.

LAUNAY, I. Le don du geste. In: Protée, vol. 29, n. 2, p. 85-96, 2001

JIMENEZ, M. Le défi esthétique de l'art tecnologique. Le portique: technique et esthétique, 1999.

LOUPPE, L. Poétique de la danse contemporaine. Bruxelas: Contredanse, 1997.

MICHEL, M. \& GINOT, I. La danse au XXe siècle. Paris: Bordas, 2002.

SORIGNET, P. E. Danser: enquête les coulisses d'une vocation. Paris: Le Seuil, 2006.

THOMAS, $\mathrm{H}$. The body, dance and cultural theory. Hampshire: Palgrave Macmillan, 2003.

WEBER, S. A. educação somática como fonte de conhecimento para a dança. In: Anais do III Congresso Brasileiro de Pesquisa em Artes Cênicas, 2004. 